\title{
Occupational Health and Safety: Provision of Appropriate Personal Protective Equipment (PPEs) for Mechanical Welding and Carpentry Workers in Mbala District of Zambia
}

\author{
Ebenezer Obi Daniel ${ }^{1,}$, Moses Mutyoka ${ }^{1}$, Paul Olaiya Abiodun ${ }^{1}$, Israel Olukayode Popoola ${ }^{2}$, \\ Kabir Yunusa Amari ${ }^{3}$, Ahmed Mamuda Bello ${ }^{1}$, Oluwole Victor Oluwalomola ${ }^{1}$, \\ Christie Omolola Adams ${ }^{1}$, Olayinka Victor Ojo ${ }^{1}$ \\ ${ }^{1}$ Department of Public Health, School of Public Health, Texila American University, Georgetown, Guyana \\ ${ }^{2}$ Department of Epidemiology and Community Health, Faculty of Clinical Sciences, College of Medicine, University of Ilorin, Ilorin, Nigeria \\ ${ }^{3}$ Department of Psychology, Faculty of Arts, Benue State University, Makurdi, Nigeria
}

Email address:

dannypressy@yahoo.com (E. O. Daniel)

${ }^{*}$ Corresponding author

\section{To cite this article:}

Ebenezer Obi Daniel, Moses Mutyoka, Paul Olaiya Abiodun, Israel Olukayode Popoola, Kabir Yunusa Amari, Ahmed Mamuda Bello, Oluwole Victor Oluwalomola, Christie Omolola Adams, Olayinka Victor Ojo. Occupational Health and Safety: Provision of Appropriate Personal Protective Equipment (PPEs) for Mechanical Welding and Carpentry Workers in Mbala District of Zambia. European Journal of Preventive Medicine. Vol. 8, No. 4, 2020, pp. 48-55. doi: 10.11648/j.ejpm.20200804.13

Received: July 11, 2020; Accepted: July 30, 2020; Published: August 13, 2020

\begin{abstract}
Small-scale enterprises and the informal sector such as mechanical, welding and carpentry workshops constitute the fastest growing economic sectors and represent the most realistic form of employment creation. These occupations are vulnerable and prone to concern themselves with survival rather than improving health and safety and as such health risks remain high in their workplaces. The objectives of this study was to assess the provision of PPEs to employees and level of enforcement of Occupational Health and Safety Act of 2010 with other regulations, guidelines and standard operational procedures in mechanical, welding and carpentry workshops in Mbala District of Northern province in the Republic of Zambia. A descriptive survey of 75 employees from small scale industries or workshops was conducted and data was collected using a questionnaire in line with key ILO thematic areas for workplaces. The results showed that the employees in these workshops were generally not complying with requirements for provision of PPEs with $28 \%$ of employees reported not being provided with PPEs. Emergency preparedness and prevention in the workplaces was also poor as none of the employees reported being trained or inducted in first aid management and $0 \%$ had first aid kit at their workshop as only $8 \%$ were inducted. It was also revealed that employees in Mechanical, Welding and Carpentry workshops in Mbala District of Zambia mostly are not complying with the provisions of the Occupational Health and Safety Act 2010 on general provisions including regulation 22 on provision and use of PPEs leading to dangerous and highly risky workplace environment. It was further revealed that all the employees from workshops interviewed have never been inspected or audited by Factory Inspectors from the Ministry of Labor and Social Services or from any other authorized bodies leading to lack of legal enforcement. The findings of this study can be used to update the health and safety conditions at different workplaces, achieving many socio-economic benefits for Zambia. Intervention plans like education, awareness, and regular medical checkups should be advocated which help in prevention and minimizing workplace exposures to occupational hazards. The identification and prevention of work-related health costs could result in substantial savings for the national health system, leading to the more sustainable social system. This study provides the baseline for elaborative studies in the future.
\end{abstract}

Keywords: Occupational Health and Safety, Personal Protective Equipment, Prevention, Emergency Preparedness 


\section{Introduction}

Workers in occupations such as carpentry, welding and mechanics workshops face a lot of hazards and risks associated with manual handling in the workplace where they highly depend on manual handling of tools and equipment in carrying out their duties. Manual handling occurs in almost all working environments; though workers in construction, agriculture, hotels and restaurants are most likely to be exposed to heavy loads. Manual handling of loads may cause cumulative disorders due to gradual and cumulative deterioration of the musculoskeletal system through continuous lifting / handling activities, e.g. low back pain. According to the Occupational Health and Safety Act, 2010 [1], the Duties of employers to employees under section 16 states that notwithstanding any other written law, an employer shall without prejudice to the generality of subsection (1), an employer shall (i) provide at the employer's expense all appropriate protective clothing or equipment (PPEs) to be used in the workplace by employees, who in the course of employment, are likely to be exposed to the risk of bodily injuries and adequate instructions in the use of such protective clothing or equipment (ii) Do for, or provide to, the employees, free of charge, anything which by law is required to be provided to those employees by the employer. (iii) A person who contravenes subsection (1) or (2) commits an offence and is liable, upon conviction, to a fine not exceeding five hundred thousand penalty units [1].

The "occupational health and safety service" means a service organized for the purpose of:

(a) Protecting employees against any health or safety hazard which may arise out of their work or the conditions in which the work is carried on;

(b) Contributing towards the employees' physical and mental adjustment, to the employees' adaptation to their work and to their assignment to work for which they are suited;

(c) Contributing to the establishment and maintenance of the highest possible degree of physical and mental wellbeing of the employees [1].

Conceptual Framework of Occupational health Of Occupational Health

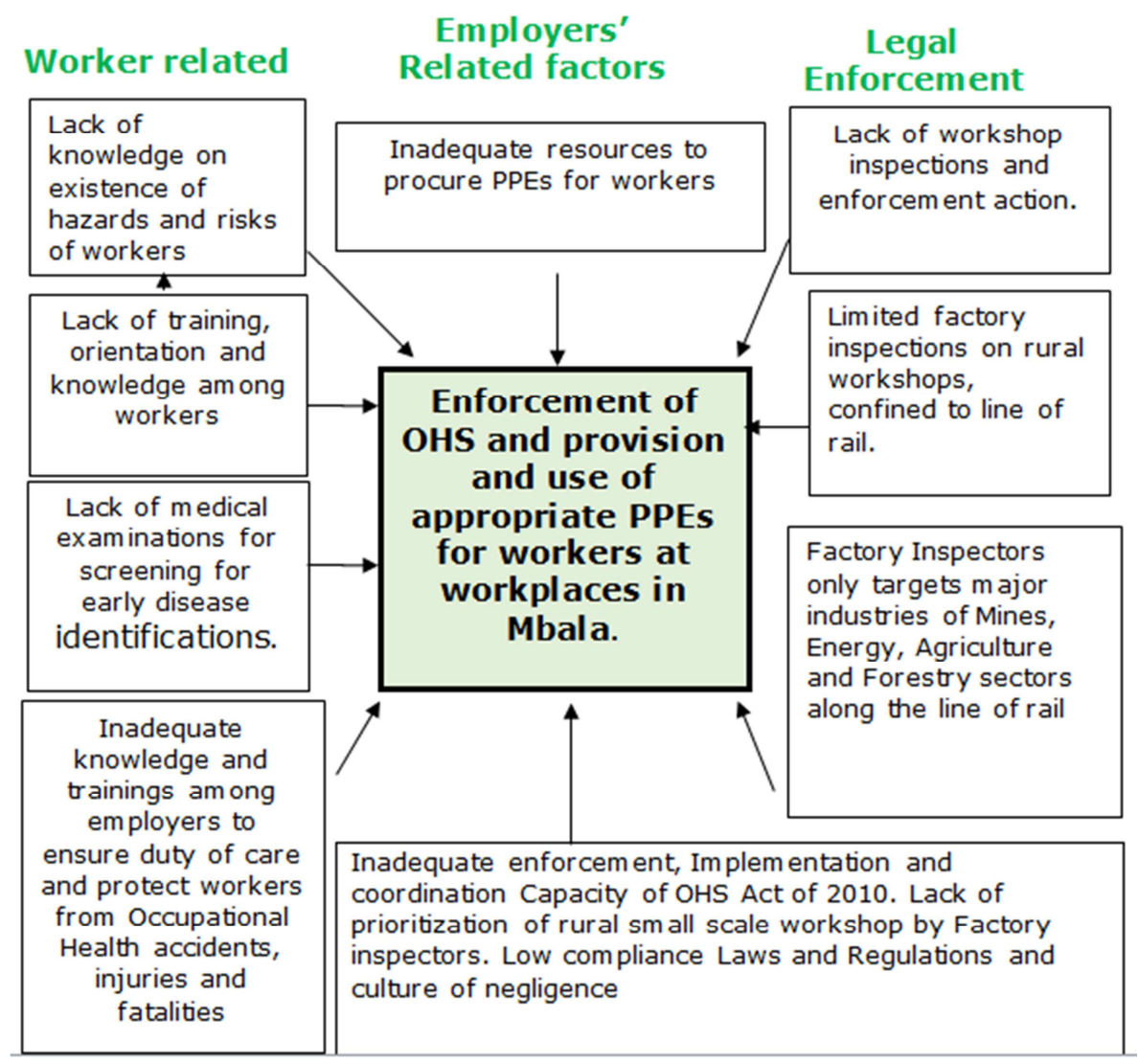

Figure 1. Conceptual Framework of Occupational Health.

Occupational accidents, injuries and conditions occur in both mechanized and manually operated tools and equipment but injuries and accidents are high in manually driven tools and equipment [1].

This research study therefore addresses the situations and conditions that prevail in workshops on Occupational Health and Safety and particularly the provision of appropriate personal Protective Equipment to all workers in the workplace environments as stated above.

According to the Personal Protective Equipment Regulations 2002 [2], "PPE" means - Any device or appliance designed to be worn or held by an individual for protection against one or more health and safety hazards: and shall also include: 
(i) A unit constituted by several devices or appliances which have been integrally combined by the manufacturer for the protection of an individual against one or more potentially simultaneous risks;

(ii) A protective device or appliance combined, separable or inseparable, with personal non-protective equipment worn or held by an individual for the execution of a specific activity; and

(iii) Interchangeable components which are essential to its satisfactory functioning and used exclusively for such equipment.

These PPEs renders the environment "safe", which means that the PPE when used and maintained in accordance with its intended purpose could not compromise the health and safety of the user without prejudice to the health and safety of other individuals, domestic animals or property, and when the context admits, cognate expressions shall be construed accordingly.

PPE intended to protect the wearer against:

(a) Mechanical action whose effects are superficial (for example gardening gloves and thimbles);

(b) Cleaning materials of weak action and easily reversible effects (for example gloves affording protection against diluted detergent solutions);

(c) risks encountered in the handling of hot components which do not expose the user to a temperature exceeding $50^{\circ} \mathrm{C}$ or to dangerous impacts (for example gloves and aprons for professional use);

(d) Atmospheric agents of a neither exceptional nor extreme nature (for example head gear, seasonal clothing and footwear);

(e) Minor impacts and vibrations which do not affect vital areas of the body and whose effects cannot cause irreversible lesions (for example light anti-scalping helmets, gloves and light footwear); and

These PPEs are to be provided as a requirement of Law under the Occupational Health and Safety Act of 2010 that provide for the establishment of health and safety committees at workplaces and for the health, safety and welfare of persons at work; provide for the protection of persons, other than persons at work, against risks to health or safety arising from, or in connection with, the activities of persons at work. Other Laws and Regulations that are also enforceable and ensure compliance are the Personal Protective Equipment Regulations 2002 and the Personal Protective Equipment at Work Regulations 1992 (as amended).

\section{Method}

The study design used was a descriptive cross sectional study. The study was conducted among workers of mechanical, welding and carpentry workshops/workplaces in Mbala District which is one of the districts of Northern Province. A Convenient sampling method was adopted in this study. The sample size was 75 employees with equal proportional representation from each sample frame.

To allow large representation of the population of each sample frame, $60 \%$ of workers from each category of the sample frame were recruited as follows; 31 workers in mechanical workshops, 14 workers in welding workshops, 27 workers in carpentry workshops and 3 workers in mechanical and welding. Therefore, a total number of 75 workers participated in the study.

Two research assistants from the Department of Public Health at Mbala Municipal Council were trained to collect data. Data were collected through the use of semi-structured questionnaires from the workers by conducting in-depth interviews. The questionnaire was written in English language, and translation in the local language (Bemba) was done during the interview sessions.

Permission was sought to carry out the research from the Town Clerk from Mbala Municipal Council and the Area Councilor of Kazimolwa ward, including the District Commissioner. The research assistants were able to explain to the respondents about the research and assure them that they are required to answer the questionnaire and schedules without force or pressure.

Consent was obtained from each respondent without coercion at the beginning of every interview session. Confidentiality was assured to all the workers involved in answering the questions or tool. Collected data were analyzed using SPSS version 21 and results were presented using descriptive statistics of tables, percentages, bar charts and pie charts where applicable.

Study Limitations

This study depends on subjective reporting of workers which can possibly be biased in some cases as the study was conducted in the rainy season, due to harsh climatic and cold weather conditions in Mbala District in rainy season, the use of PPEs and perception of workplace exposures among study subjects might vary.

Being a survey study; it might reflect the attitude and perception of participants for the reported use of PPEs while the reported use and need for PPEs as well as the workplace exposures among study subjects in other regions might be different having diverse attitudes and perception even though exposed to a similar level of workplace exposures, hazards, and risks.

\section{Results}

The chapter presents the type of data that was used and the data has been presented in terms of charts and tables. This chapter also used research objective to discuss the research findings on the topic under study.

Type of Work

The findings on figure 2 revealed that, majority employees were working in mechanical workshops with 31 employees representing $41.3 \%$ from the total number of 75 employees interviewed, followed by 27 (36\%) employees in carpentry workshop, then $14(18.7 \%)$ employees were from welding workshops and finally $3(4 \%)$ employees were from both mechanical and welding workshops. 


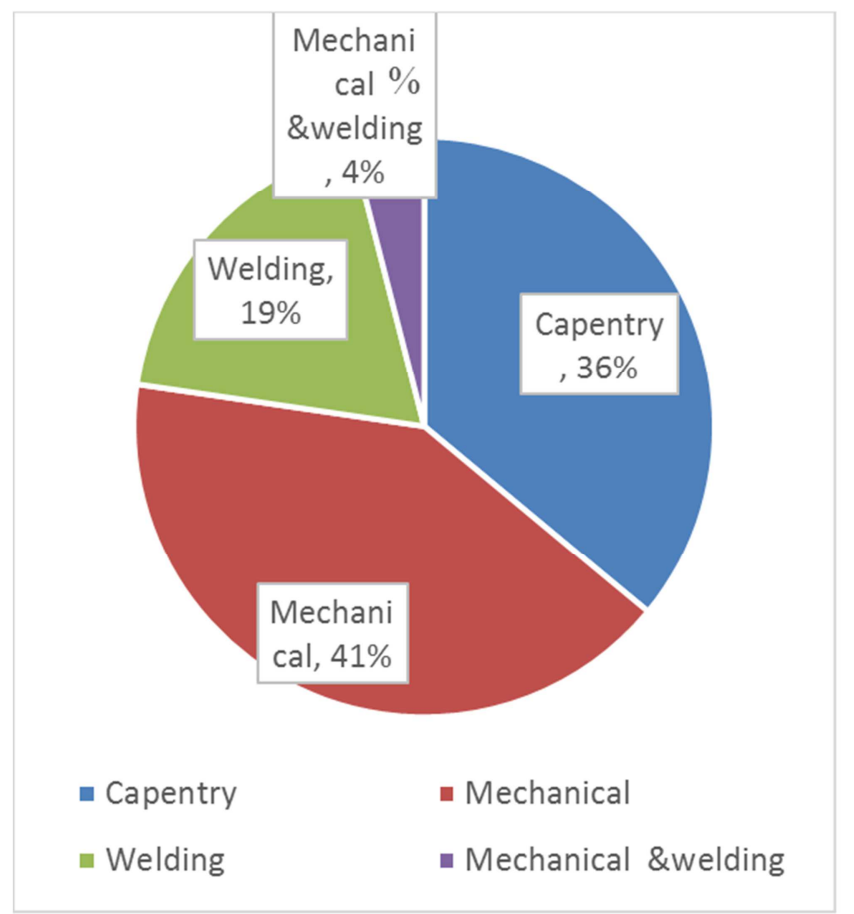

Figure 2. Type of Work.

The data on employment levels in the small scale industries in Mbala District indicated that the maximum of 4 employees are employed per workshop while $13 \%$ of employees had 1 employee per workshop.

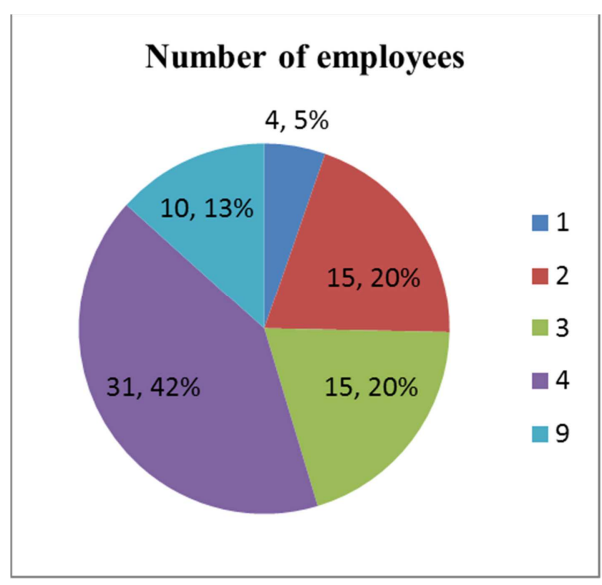

Figure 3. Number of Employees.

The data below indicated that $0 \%$ of employees have written Safety programme, Occupational Health and Safety Manual or Safety Management System. Further the study revealed that $0 \%$ of employees indicated having a formal system of reporting, recording and investigation of incidents, injuries and illnesses. The data also showed that only $8 \%$ of workshops are inspected by inspectors from relevant authorities. The data above therefore indicated serious systems and procedural gaps in the standard operations procedures (SOP) that leads to compromised workplace environments exposing employees to workplace hazards and posing high risks of accidents and injuries.

Table 1. Questions.

\begin{tabular}{|c|c|c|c|c|}
\hline $\mathbf{S} / \mathbf{N}$ & QUESTION & YES & NO & PERCENTAGE \\
\hline 1 & $\begin{array}{l}\text { Does a workshop have a Written Safety Programme, Occupational Health and Safety (OHS) } \\
\text { Manual or Safety Management System? }\end{array}$ & 0 & 75 & $0 \%$ \\
\hline 2 & $\begin{array}{l}\text { Does the workshop have a Formal System of Reporting, Recording and Investigation of } \\
\text { Incidents, Injuries and Illnesses? }\end{array}$ & 0 & 75 & $0 \%$ \\
\hline 3 & Does the workshop Conduct Project or Work Site Safety Inspection & 6 & 69 & $8 \%$ \\
\hline
\end{tabular}

The data in table 2 below revealed that, majority employees representing $67 \%$ conducted inspections on monthly basis which is highly recommended.

Table 2. Inspections/Audits Conducted from workshops conducting inspections.

\begin{tabular}{llll}
\hline How often are inspections/audits conducted & Frequency & \% \\
\hline & Monthly & 4 & $67 \%$ \\
& Quarterly & 2 & $33 \%$ \\
Total & & 6 & 100 \\
\hline
\end{tabular}

Table 3 revealed that majority employees were not inducted in the following critical categories: Only $49 \%$ of employees were inducted in Fire protection, only $41 \%$ of the employees were inducted in Respiratory protection and only $3 \%$ of the employees had systems of recording trainings, qualifications, competencies and licenses of its employees. These gaps revealed in lack of induction are serious in developing capabilities or capacities in understanding and complying with procedures as key element of accident and injury prevention through early hazard identification.

Figure 4 revealed that PPE provision in all categories was below $30 \%$ indicating a serious problem of injury prevention and violation of the Laws and regulations in the provision and utilization of PPEs.

Table 3. Induction of Workers.

\begin{tabular}{|c|c|c|c|c|c|}
\hline \multirow{2}{*}{$\mathbf{S} / \mathbf{N}$} & \multirow{2}{*}{ QUESTIONS ON INDUCTION } & \multicolumn{2}{|c|}{ YES } & \multicolumn{2}{|c|}{ NO } \\
\hline & & $\mathbf{N}$ & $\%$ & $\mathbf{N}$ & $\%$ \\
\hline 1 & Are Workers Inducted? & 73 & 97 & 2 & 3 \\
\hline 2 & Does the Induction Programme Cover Foot Protection & 71 & 97 & 2 & 3 \\
\hline 3 & Does the Induction Programme Cover Fire Protection & 36 & 49 & 37 & 51 \\
\hline 4 & Does the Induction Programme Cover Hand Protection & 62 & 84 & 11 & 16 \\
\hline 5 & Does the Induction Programme Cover Respiratory Protection & 30 & 41 & 43 & 59 \\
\hline 6 & Does the Induction Programme Cover Scaffolding Protection & 2 & 3 & 71 & 97 \\
\hline
\end{tabular}




\begin{tabular}{|c|c|c|c|c|c|}
\hline \multirow{2}{*}{$\mathbf{S} / \mathbf{N}$} & \multirow{2}{*}{ QUESTIONS ON INDUCTION } & \multicolumn{2}{|c|}{ YES } & \multicolumn{2}{|l|}{ NO } \\
\hline & & $\mathbf{N}$ & $\%$ & $\mathbf{N}$ & $\%$ \\
\hline 7 & Does the Induction Programme Cover Housekeeping Protection & 68 & 93 & 5 & 7 \\
\hline 8 & Does the Induction Programme Cover Eye Protection & 59 & 80 & 14 & 20 \\
\hline 9 & Does the Induction Programme Cover First Aid Facilities & 43 & 58 & 30 & 42 \\
\hline 10 & Does the Induction Programme Cover Emergence Procedures & 58 & 79 & 15 & 21 \\
\hline 11 & Does the Induction Programme Cover Hazardous Substances & 65 & 89 & 8 & 11 \\
\hline 12 & Does the Induction Programme Cover Excavation and Trenching & 4 & 5 & 69 & 95 \\
\hline 13 & Does the Induction Programme Cover Confined Spaces & 29 & 39 & 44 & 61 \\
\hline 14 & Does the Induction Programme Cover Working at Heights & 4 & 5 & 69 & 95 \\
\hline 15 & Does the Induction Programme Cover Signs, Barricades and Flagging & 24 & 32 & 49 & 68 \\
\hline 16 & Does the Induction Programme Cover Electrical Safety & 37 & 50 & 36 & 50 \\
\hline 17 & Does the Induction Programme Cover Rigging and Crane Safety & 17 & 23 & 56 & 77 \\
\hline 18 & Does the Induction Programme Cover Incidents/Injury Reporting & 71 & 97 & 2 & 3 \\
\hline 19 & Does the Induction Programme Cover Consultation Process & 62 & 84 & 11 & 16 \\
\hline 20 & $\begin{array}{l}\text { Does the workshop have a System of Recording Training, Qualification, Competencies } \\
\text { and Licences of its Employees }\end{array}$ & 2 & 3 & 73 & 97 \\
\hline
\end{tabular}

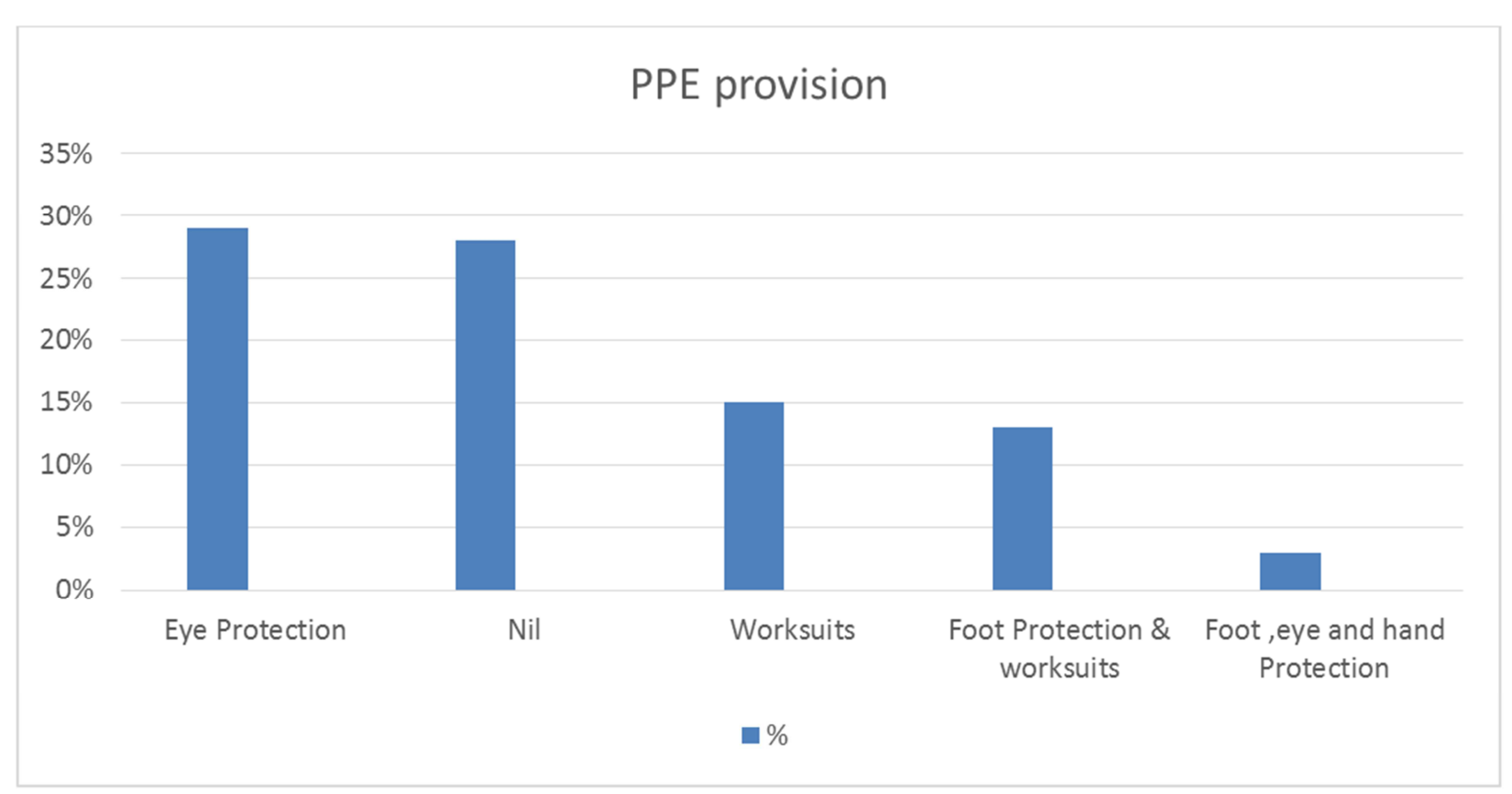

Figure 4. Personal Protective Equipment (PPEs) provided for Employees.

How is the Issue and Use of PPEs Controlled?

93.4\% of employees indicated there is no system to control issuance or provision of PPEs to employees leading poor replenishment and distribution risking the safety of employees.

Table 4. Issue and Use of PPEs.

\begin{tabular}{lll}
\hline & Frequency & Percent \\
\hline Employees are only given once when they begin work. They are reused every time they begin work & 1 & 1.3 \\
Monthly & 2 & 2.7 \\
Not available & 70 & 93.4 \\
When they wear out & 2 & 2.7 \\
Total & 75 & 100.0 \\
\hline
\end{tabular}

\section{Questions on Policy}

The findings on Table 5 revealed that $0 \%$ of employees' indication having register of hazardous substances, $0 \%$ of employees having any system to manage hazardous substances, $0 \%$ of employees indicated having alcohol and other drug policy at workplaces and $0 \%$ of employees showed having injury management/rehabilitation policy/programme for employees who suffer work related injury/illnesses. 
Table 5. Questions on Policy.

\begin{tabular}{|c|c|c|c|c|}
\hline $\mathbf{S} / \mathbf{N}$ & QUESTION & YES & NO & PERCENTAGE \\
\hline 1 & Does the Company Keep Register of Hazardous Substances & 0 & 75 & $0 \%$ \\
\hline 2 & Does the workshop have a System to Manage Hazardous Substances & 0 & 75 & $0 \%$ \\
\hline 3 & Does the workshop have an Alcohol and other Drugs Policy in Places & 0 & 75 & $0 \%$ \\
\hline 4 & $\begin{array}{l}\text { Does the workshop have an Injury Management/Rehabilitation Policy/Program for Employees who } \\
\text { Suffer Work Related Injury/Illness }\end{array}$ & 0 & 75 & $0 \%$ \\
\hline
\end{tabular}

The Type of Occupational Conditions or Diseases that can be contracted at Workplace.

The findings revealed that $29.3 \%$ of employees recognized physical injuries with the lowest recognized being physical injuries, eye damage and backache at $2.7 \%$. Generally, the level of knowledge on various forms of injury is very low with percentage falling below $50 \%$ in all categories.

Table 6. The Type of Occupational Conditions or Diseases that can be contracted at Workplace.

\begin{tabular}{lll}
\hline & Frequency & Percent \\
\hline Physical injuries & 22 & 29.3 \\
Physical injuries and eye damage & 20 & 26.7 \\
Physical injuries and respiratory diseases & 16 & 21.3 \\
\hline
\end{tabular}

\begin{tabular}{lll}
\hline & Frequency & Percent \\
\hline Physical injuries and skin diseases & 6 & 8.0 \\
Physical injuries, eye damage and backache & 2 & 2.7 \\
Physical injuries, eye damage and respiratory & 9 & 12.0 \\
diseases & 75 & 100.0 \\
Total & 75 \\
\hline
\end{tabular}

Benefits of Personal Protective Equipment (PPEs) in Workplace Environment

The findings on table 7 revealed that, majority of employees understand the benefits of PPEs with $90.7 \%$ indicating that it protects workers from injuries, prevent from diseases or condition and reduce or protect workers from contact with hazardous substances.

Table 7. Benefits of Personal Protective Equipment (PPEs) in Workplace Environment.

\begin{tabular}{lll}
\hline & Fercent & \\
\hline Protect workers from injuries and prevent from diseases or condition & 6 & \\
Protect workers from injuries, prevent from diseases or condition and boost workers morale and promote productivity & 1 & \\
Protect workers from injuries, prevent from diseases or condition and reduce or protect workers from contact with & 1.3 & 68 \\
hazardous substances & 90.7 & 100.0 \\
Total & 75 \\
\hline
\end{tabular}

\section{Discussion}

The results in this study revealed that $28 \%$ of employees interviewed had no PPEs. This is in close tandem with the results of the study carried out in the healthcare industry in 2007 that revealed that lack of PPE or non-availability was responsible for $37 \%$ of cases of noncompliance with PPE regulations [3]. In a similar study conducted in Jeddah in the Kingdom of Saudi Arabia [4], on the availability and use of PPEs as well as self-reported occupational exposures among workers in surveyed small industries in Jeddah, reported use of different PPEs in descending order was; knee joints mats $(50 \%)$, welding shields $(50 \%)$, safety glasses $(33.3 \%)$, gloves $(27.5 \%)$, face masks $(26.5 \%)$, safety shoes $(10.8 \%)$ and earplugs/ muffs $(8.8 \%)$. While this study revealed that $12 \%$ of the self-reported employees were provided with foot protection compared to the results in Jeddah which reported safety shoes accounted to $10.8 \%$ of the employees in similar small scale industries. On the other hand, the study in Jeddah recorded high use of welding shields at 50\% and safety glasses at $33.3 \%$ which is concordantly comparable to this study with $29 \%$ use eye protection. In the Jeddah study, looking at the availability and use of PPEs in small scale industries the maximum reported positive response of $50 \%$ was for the use of knee joint protection mats while working under the vehicles and welding shields whereas the lowest positive response of $8.8 \%$ was reported for the use of earplugs and muffs for the protection of ears against the noise compared to this study where employees with Eye protection were 22 representing 29.3\%, followed by Work suits 11 employees representing 14.7\%, then employees with Foot protection and work suits were 10 representing $13.3 \%$, employees with Foot protection were 9 representing 12.0\%, employees with Foot, eye and hand protection were 2 representing $2.7 \%$ and those without PPEs were 21 representing 28.0\%. Another study in Ghana reported that only $8 \%$ of welders were using goggles while the use of face masks was 56\% among sprayers (Monney et al., 2014) [5] which is considerably higher than the findings of this study in Mbala District of the Republic of Zambia where the employees with eye protection were $29.3 \%$. In the Jeddah study none of the studied subjects were found to use the full complement of the required PPEs i.e. boots, shields, goggles, masks, overalls, gloves, and respirators as compared with this study result with $28 \%$ of the employees interviewed had completely no PPEs.

In Jeddah study, there was a reported information gap on knowledge of occupational hazards, risks and their health effects and utilization and effectiveness of safety measures among small-scale workshops employees (Ahmad et al., 2016) [6] in contrast to this study that revealed a high knowledge levels with $90.7 \%$ of employees correctly indicated that PPEs protect workers from injuries, prevent 
from diseases or condition and reduce or protect workers from contact with hazardous substances. The study found that welders were exposed to welding hazards such as intense bright light, heat, noise, fumes and gases. Another study conducted in Zambia by Zgambo [7] revealed that the majorities (98\%) of welders were aware of at least one type of welding hazard or PPE, about $2 \%$ were not aware of any hazards or any personal protective measures. None of the welders used all the recommended PPE at any time during their work. Zgambo J (2005) [7] which is in total agreement with the findings of this study which indicated that knowledge levels on PPEs was also high at $90.7 \%$.

The Jeddah survey showed that policies and measures for delivery of OSH services are limited and deficient for the studied population even though the laws, regulations, and policies are in place but their implementation, inspection, and audits for proper adherence to standards are needed to be improved in the studied workshops which was true compared to this study where it was found that $100 \%$ of small scale industries have never been inspected and audited by Government Inspectors from either Ministry of Labour and Social Services or Local Authority resulting in lack of professional staff inductions or trainings, Lack of records management, lack of reporting systems and lack of first aid facilities or services including rehabilitation services for the injured.

Another study in Ethiopia was conducted from February to May, 2016 with a total of 219 individuals recruited in the study to identify factors associated with work related injuries aiming at assessing the magnitude of work related injury and associated factors among small scale industrial workers in Mizan-Aman town, Bench Maji Zone, Southwest Ethiopia that revealed that the respondents who used PPEs properly and consistently were $82(37.4 \%)$. The results in the Ethiopia study that indicated that $37.4 \%$ of proper and consistent use of PPEs is in close agreement with this study that revealed that $29 \%$ of the employees had full eye protection with $12 \%$ of employees provided with foot protection while $28 \%$ of employees interviewed had no PPEs concluding that use of PPEs in Mbala District is poor that includes other Countries like Ethiopia.

Furthermore, the Ethiopia study revealed that only 31 $(14.2 \%)$ of the respondents had occupational safety and health training compared to the findings of this study indicated appreciable percentage of $49.3 \%$ of employees inducted in Fire protection, $41.1 \%$ of the employees were inducted in Respiratory protection and only $2.7 \%$ of the employees had systems of recording trainings, qualifications, competencies and licenses of its employees. The $92 \%$ lack of induction revealed in this study is also in line with only $14.2 \%$ of respondents trained in the Ethiopian study among employees working in small scale industries that means $85.8 \%$ were also not trained.

In Australia a report on six existing Safe Work data sources and one Australian Bureau of Statistics (ABS) [8] data source that focused on exposure to hazards in construction, provision of control measures, other work health and safety practices and work health and safety attitudes and perceptions that may be relevant to work health and safety practices in the industry revealed that thirty nine per cent $(39 \%)$ of construction employers did not provide any work health and safety training to their employees during 2012. The report further showed that $45 \%$ of employers in small businesses did not provide any training. These findings in the Australian report regarding small scale industries are in very close agreement with this study that revealed that only 6 out of 75 employees interviewed indicated having conducted induction training to the employees representing only $8 \%$.

These low data in training workers was also in the findings from the 2012 regulatory burden survey in Australia that over half of small business indicated that they provided internal staff training over the past twelve months. The Australian study also indicated that worker consultations among construction workers generally had lower levels of agreement which is in contrast with this study that revealed that $85 \%$ of employees embrace consultative processes.

In Botswana a study was conducted on Occupational health and safety survey in small-scale clothing enterprises in Gaborone, by Sanyi George Gabe [9] which revealed that there was generally a very poor use of PPE. Most workplaces did not provide protective overcoats or aprons (94.4\%), dust masks, ear plugs, thimble and gloves (100\%), while up to $94.4 \%$ did not maintain and replace PPE regularly and $63.9 \%$ did not use built-in guards or built-in hazard controls on their machines and equipment as a replacement for PPE. These results in the Gaborone study are in line with findings of this study that also revealed that $28 \%$ of employees were not provided with any form of PPEs while appropriate PPE provisions in other categories were equally low. The Gaborone study further revealed that performance of all the workplaces inspected for use of protective clothing and equipment was scored not a single positive response was scored for almost $78 \%$ of the workplaces, while two measure variable conditions were present in only $5.6 \%$ of the workplaces that further compliments the findings of this study.

The Gaborone study further revealed that there was generally a poor compliance to OHS standards in relation to every working place having a copy of OHS Act (Factories Act) which is in tandem with this study finding that revealed zero per cent $(0 \%)$ availability of any documents at all workplaces.

The results of the study indicated further that all workplaces did not conduct risk assessment. Most (88.2\%) did not instruct their employees in the use of machinery and equipment and $75 \%$ did not train their workers, which is in total agreement with this study that revealed that only 6 employees out 75 employees interviewed were inducted leading to low safety knowledge among employees that may compromise their safety.

\section{Conclusion}

In conclusion, the key findings of this study are that 
provision of appropriate PPEs to employees working in welding, mechanical and carpentry workshops in Mbala of the Northern Province in the Republic of Zambia is very low in all key categories exposing the employees to numerous physical, chemical and accidental hazards. This study confirmed lack of inspections and audits of the small scale industries in Mbala by inspectors from the Ministry of Labour and other Authorities leading to lack of enforcement of laws, regulations, guidelines and prescribed standards coupled with lack of employee induction leading to low knowledge levels on safety procedures putting their lives to higher risks of exposure to hazards, accidents and injuries.

It can then be inferred that provision of appropriate PPEs to employees in welding, mechanical and carpentry workshops is very poor and the situation was propelled by lack of enforcement intervention characterized by lack of inspection and workshop audits.

It is therefore recommended that the Government of the Republic of Zambia should decentralize the functions of Factory Inspectors from the Ministry of Labour to the Ministry of Local Government and Ministry of Health by recognizing and empowering Environmental Health Officers found in Local Authorities in all the Districts in the Republic of Zambia to strengthen routine inspection and enforcement activities in order to protect and safeguard the lives of vulnerable employees.

\section{References}

[1] Occupational Health and Safety Act, 2010. www.parliament.gov.zm/node/3409.

[2] The Personal Protective Equipment Regulations 2002. www.legislation.gov.uk/uksi/2002/1144/contents.

[3] RIDDOR (2015). www.hse.gov.uk/pubus/indg453.htm.

[4] N. Ali, I. M. I. Ismail, S. A. M. A. S. Eqani, G. Malarvannan, M. W. Kadi, M. Rehan, A. Covaci (2016). Brominated and organophosphate flame retardants in indoor dust of Jeddah, Kingdom of Saudi Arabia: implications for human exposure Sci. Total Environ., 569, pp. 269-277.
[5] I. Monney, B. Dwumfour-Asare, I. Owusu-Mensah, R. A. Kuffour (2008) Occupational health and safety practices among vehicle repair artisans in an urban area in Ghana.

[6] I. Ahmad, M. Rehan, M. Balkh your, M. Abbas, J. Basahi, T. Almeelbi, I. M. Ismail (2016) Review of environmental pollution and health risks at motor vehicle repair workshops challenges and perspectives for Saudi Arabia.

[7] Zgambo, J., (2015) Occupational hazards and use of personal protective equipment among small scale welders in Lusaka, Zambia (Master's thesis, The University of Bergen).

[8] Australian Bureau of Statistics. www.abs.gov.au.

[9] Gabe SG, (2010). Occupational Health and Safety Survey in small Scale Clothing Enterprises in Gaborone (Botswana). University of Limpopo (Medunsa Campus).

[10] Health and Safety Executive (UK): Health and Safety in Motor Vehicle Repair and associated industries. HSG 261, HSE Books, 2009, ISSBN 9780717663088.

[11] T. Acheampong and R. Akumperigya, (2018). "Offshore risk regulation: a comparative analysis of regulatory framework in Ghana, the United Kingdom and Norway," Energy Policy, vol. 113, pp. 701-710.

[12] H. Toseafa, R. Bata, and E. Toseafa, (2018). "Incidence of occupational health hazards and safety culture at Tema Oil Refinery (TOR) in Ghana: exploring the symbiotic relationship," British Journal of Environmental Sciences, vol. 6 , no. 4, pp. 58-74.

[13] F. Laal, R. Mirzaei, M. S. Behdani, M. Mohammadi, and K. Khodami, (2017) "Evaluation of the influence of ergonomic intervention on the musculoskeletal disorders of Zahedan tailors," International Journal of Occupational Safety and Ergonomics, vol. 23, no. 3, pp. 380-385.

[14] Dong, F. Wang, H. Li, L. Ding, and H. Luo (2018). "Knowledge dynamics-integrated map as a blueprint for system development: applications to safety risk management in Wuhan metro project," Automation in Construction, vol. 93, pp. 112-122.

[15] A. Lette, A. Ambelu, T. Getahun, and S. Mekonen, (2018). “A survey of work-related injuries among building construction workers in southwestern Ethiopia," International Journal of Industrial Ergonomics, vol. 68, pp. 57-64. 